\title{
High prevalence of hyposalivation in individuals with neurofibromatosis 1: a case-control study
}

\author{
Karin Soares Cunha ${ }^{1,2^{*}}$, Rafaela Elvira Rozza-de-Menezes ${ }^{1,2}$, Eloá Borges Luna ${ }^{1,2}$, \\ Lilian Machado de Sousa Almeida ${ }^{1,2}$, Raquel Richelieu Lima de Andrade Pontes ${ }^{1}$, Paula Nascimento Almeida ${ }^{1,2}$, \\ Letícia Vidaurre de Aguiar ${ }^{3}$ and Eliane Pedra Dias ${ }^{1,4}$
}

\begin{abstract}
Background: Neurofibromatosis type 1 (NF1) is one of the most common genetic diseases in humans and has widely variable expressivity. Oral manifestations are common, but there are no studies that investigated functional alterations in salivary glands in NF1. Our aim was to evaluate the salivary flow rate in NF1 individuals, comparing to a control group, and to investigate the possible causes and some consequences of salivary gland alteration.

Methods: This is a case-control study that evaluated the salivary flow rate of NF1 individuals $(n=49)$ and compared to an age and sex-matched control group. We have also investigated the possible causes and consequences of hyposalivation in NF1 individuals through anamnesis, a specific questionnaire, physical examination, tongue coating evaluation and cytopathological exam to assess the prevalence of oral candidiasis.

Results: Hyposalivation at rest was present in 59\% (29/49) of NF1 individuals in contrast to 22\% (11/49) in the control group, being statistically significant $(P<0.0001$; Wilcoxon rank-sum test). The analysis of the adjusted residual showed that the prevalence of hyposalivation in NF1 individuals (46.9\%) was 4-fold higher than in controls (10.2\%).

None of the possible causes of hyposalivation (medications, low liquid intake, caffeinated or stimulant drink use, mouth breathers, alcohol, smoke and plexiform neurofibroma close to or involving major salivary glands areas) had important impact on the salivary flow rate in NF1 individuals.
\end{abstract}

Conclusions: Hyposalivation may be a consequence of NF1, as occurs in other genetic diseases. More studies are necessary to understand if there is and what is the relationship between NF1 and hyposalivation.

Keywords: Neurofibromatosis 1, Salivary glands, Xerostomia, Oral manifestations

\section{Background}

Neurofibromatosis 1 (NF1, OMIM 162200) is one of the most common genetic diseases and has widely variable expressivity [1]. Oral manifestations are common, [2-6] but there are no studies that investigated functional alterations in salivary glands in NF1. Our aim was to evaluate the salivary flow rate in NF1 individuals, comparing to a control group, and to investigate the possible causes and some consequences of salivary gland alteration.

\footnotetext{
* Correspondence: karingcunha@gmail.com

'Postgraduate Program in Pathology, School of Medicine, Universidade Federal Fluminense, Niterói, RJ, Brazil

${ }^{2}$ Neurofibromatosis National Center (Centro Nacional de Neurofibromatose), Rio de Janeiro, RJ, Brazil

Full list of author information is available at the end of the article
}

\section{Methods}

This case-control study was approved by the Ethics Committee (\#31640/2012) and conducted at Oral Diagnosis Ambulatory and Pathological Anatomy Service of Antônio Pedro University Hospital of Universidade Federal Fluminense, Brazil.

The study group was composed of 49 NF1 individuals, according to clinical criteria [7]. To compare the sialometry values of NF1 individuals, a sex and age-matched control group $(\mathrm{n}=49)$ composed by non-NF1 individuals was included. Data about smoking, alcohol use, and intake of hyposalivation-inducing drugs was obtained from both groups.

Sialometry (unstimulated whole saliva flow rate) was performed between 8:00-11:30 AM and the participants 
did not ingest food or liquids 1 hour before the exam. After discarding all the saliva present in the mouth, saliva was collected for 5 minutes without stimulus. The salivary flow rate $(\mathrm{mL} / \mathrm{min})$ was calculated and classified: normal: $\geq 0.3$; low: $\geq 0.1$ and $<0.3$; very low: $<0.1$.

Tongue coating was evaluated according to previous studies $[8,9]$, using digital photographs. The tongue dorsum area was divided into nine equal sections and each section was assigned a value: $0=$ no; $1=$ thin, $2=$ thick coating. The sum of the results of each section was calculated, divided by 18 and multiplied by 100 to achieve the tongue coating index (TCI) percentage score.

Oral candidiasis was investigated by clinical and cytopathology exam through scrapping the tongue dorsum with a cytobrush. Glass slides stained with Papanicolaou and Periodic Acid-Schiff were analyzed according to specific criteria [10].

NF1 participants also answered to a questionnaire (Table 1).

\section{Results}

Additional files 1, 2 and 3 show details of the results. Table 2 summarizes the sample characteristics. There was no heterogeneity between the study and control group according to smoking, alcohol use and intake of medications that could cause hyposalivation. Four $(8 \%)$ NF1 participants had plexiform neurofibromas close to or involving the major salivary glands areas and only one (25\%) had hyposalivation.

In NF1 individuals, 59\% (29/49) had hyposalivation; $32 \%(16 / 49)$ had severe hyposalivation. In the control group, 22\% (11/49) of individuals had hyposalivation; $8 \%$ $(4 / 49)$ presented severe hyposalivation. There was a statistically significant difference between the sialometry values of the study and control group $(P<0.0001$; Wilcoxon rank-sum test). There was a statistically significant

Table 1 Questionnaire used in the study group (with NF1)

\begin{tabular}{|c|c|c|}
\hline Questions & Resp & onse \\
\hline Oral Dryness Questionnaire & Yes & No \\
\hline 1. Do you fell dry oral mucosa sensation? & Yes & No \\
\hline 2. Do you feel dry lips sensation? & Yes & No \\
\hline 3. Do you have difficult to swallow dry food? & Yes & No \\
\hline 4. Do you drink liquids to aid swallowing dry food? & Yes & No \\
\hline 5. Do you feel change in saliva viscosity? & Yes & No \\
\hline 6. Do you feel a decreased amount of saliva in your mouth? & Yes & No \\
\hline $\begin{array}{l}\text { 7. Do you feel enough or increased amount of saliva in your } \\
\text { mouth? }\end{array}$ & Yes & No \\
\hline Other Questions & Yes & No \\
\hline 8. Do you intake at least 2 liters of liquid daily? & Yes & No \\
\hline 9. Do you commonly drink caffeinated or stimulant drinks? & Yes & No \\
\hline 10. You are a mouth breather? & Yes & No \\
\hline
\end{tabular}

Table 2 Summary of the sample characteristics

\begin{tabular}{llll}
\hline Data & $\begin{array}{l}\text { Study group } \\
\text { (with NF1) }\end{array}$ & Control group & $\boldsymbol{P}^{*}$ \\
\hline Number & 49 & 49 & \\
Age (years) & $42.5 \pm 14.8^{\dagger}$ & $42.5 \pm 14.8^{\dagger}$ & - \\
Sex (female/male) & $35 / 14(2.5: 1.0)$ & $35 / 14(2.5: 1.0)$ & - \\
Smoker & $4(8 \%)$ & $9(18 \%)$ & 0.227 \\
Alcohol user & $8(16 \%)$ & $10(20 \%)$ & 0.774 \\
Hyposalivation-inducing drugs & $14(28 \%)$ & $18(36 \%)$ & 0.344 \\
\hline
\end{tabular}

NF1, Neurofibromatosis 1.

${ }^{*} P$ value is from McNemar $\mathrm{X}^{2}$ test; ${ }^{\dagger}$ Results indicate

mean \pm standard deviation.

association between NF1 individuals and presence of hyposalivation $\left(P=0.001\right.$; McNemar's $X^{2}$ test). The analysis of the adjusted residual showed that the prevalence of hyposalivation in NF1 individuals (46.9\%) was 4-fold higher than in controls (10.2\%).

Forty-six NF1 participants answered to the questionnaire. The number of positive answers per individual to the oral dryness questions was assessed to investigate them as possible predictor of hyposalivation. The results are shown in Tables 3-4.

Oral candidiasis was present in 22\% (11/49) of NF1 individuals. Of these, $54 \%(6 / 49)$ had no clinical signs or symptoms of candidiasis, 36\% (3/49) had erythematous and $9 \%(1 / 49)$ pseudomembranous candidiasis.

Fifty-five percent (27/49) of NF1 individuals had more than $50 \%$ and $16 \%$ had more than $80 \%$ of the tongue covered by coating. The mean of TCI was $50 \%$ (standard

Table 3 Hyposalivation and oral dryness questionnaire in study group (with NF1)

\begin{tabular}{|c|c|c|c|}
\hline \multirow{2}{*}{$\begin{array}{l}\text { Oral Dryness } \\
\text { Assessment } \\
\text { Questionnaire }\end{array}$} & \multicolumn{3}{|l|}{ UWSFR } \\
\hline & $\begin{array}{l}\text { Hyposalivation } \\
(\%)\end{array}$ & $\begin{array}{l}\text { OR } \\
\text { (IC 95\%) }\end{array}$ & $P^{*}$ \\
\hline $\begin{array}{l}\text { 1. Do you fell dry oral } \\
\text { mucosa sensation? }\end{array}$ & $9(18)$ & $1.8(0.4-7.3)$ & 0.51 \\
\hline $\begin{array}{l}\text { 2. Do you feel dry lips } \\
\text { sensation? }\end{array}$ & $10(20)$ & $0.8(0.2-2.6)$ & 0.76 \\
\hline $\begin{array}{l}\text { 3. Do you have difficult to } \\
\text { swallow dry food? }\end{array}$ & $6(12)$ & $1.5(0.3-7)$ & 0.71 \\
\hline $\begin{array}{l}\text { 4. Do you drink liquids to } \\
\text { aid swallowing dry food? }\end{array}$ & $14(28)$ & $1.8(0.5-6.1)$ & 0.37 \\
\hline $\begin{array}{l}\text { 5. Do you feel change in } \\
\text { saliva viscosity? }\end{array}$ & $11(22)$ & $1.9(0.5-6.9)$ & 0.36 \\
\hline $\begin{array}{l}\text { 6. Do you feel a decreased } \\
\text { amount of saliva in your } \\
\text { mouth? }\end{array}$ & $8(16)$ & $0.9(0.2-3.2)$ & 0.88 \\
\hline $\begin{array}{l}\text { 7. Do you feel enough or } \\
\text { increased amount of saliva } \\
\text { in your mouth? }\end{array}$ & $3(6)$ & $0.4(0.09-2)$ & 0.42 \\
\hline
\end{tabular}


Table 4 Score of positive answers from oral dryness assessment questionnaire according to hyposalivation in study group (with NF1)

\begin{tabular}{llll}
\hline $\begin{array}{l}\text { Number of } \\
\text { positive answers* }\end{array}$ & UWSFR & \\
\cline { 2 - 4 } & Hyposalivation (\%) & OR (IC 95\%) & $\boldsymbol{P}^{* *}$ \\
\hline None & $7(14)$ & $0.9(0.2-3.7)$ & 0.97 \\
One & $8(16.3)$ & $0.6(0.1-3)$ & 0.7 \\
Two & $4(8.1)$ & $0.4(0.1-2.1)$ & 0.45 \\
Three & $7(14)$ & $2.9(0.5-16.2)$ & 0.27 \\
Four & $2(4)$ & $1.7(1.3-2.2)$ & 0.5 \\
Five & $2(4)$ & $1.4(0.1-17.1)$ & 1.0 \\
Six & $2(4)$ & $0.6(0.8-5.3)$ & 1.0
\end{tabular}

UWSFR, Unstimulated whole saliva flow rate; OR (IC 95\%), Odds ratio and 95\% of confidence interval.

${ }^{*}$ Considering the first six questions of the Oral Dryness Questionnaire, ${ }^{* *} P$ value is from Qui-Square analysis or Fisher's exact test.

deviation $=26.7$, median $=50$, first quartile $=25$, third quartile $=72$ ).

Any of the investigated variables were associated with hyposalivation in NF1 individuals (Table 5).

\section{Discussion}

We showed that NF1 individuals present high prevalence $(59 \%)$ of hyposalivation comparing to a control group $(P<0.001)$, with a proportion 4 -fold higher than the controls.

Xerostomia often occurs when sialometry value is reduced by about $50 \%$ [11]. Due to this lack of correlation between xerostomia and hyposalivation, some authors have investigated whether positive answers to other questions related to the dry mouth symptoms have correlation with sialometry values [11]. In our study, hyposalivation was not associated with xerostomia in NF1 individuals, neither with other questions from the oral dryness questionnaire.

Xerostomia can also occur in individuals with normal sialometry values $[11,12]$. It can occur in mouth breathers or because of changes in the sialochemistry, viscoelastic properties of saliva or by sensory alterations. In the present study, there was no NF1 individual who complained of xerostomia and did not present hyposalivation.

Saliva exerts many functions in oral cavity, including the control of the composition of the microflora. We found $22 \%$ of NF1 participants with cytological evidence of oral candidiasis and $55 \%$ with $50 \%$ of the tongue covered by coating, but none were associated with hyposalivation.

None of the investigated causes of hyposalivation (medications, low liquid intake, caffeinated or stimulant drink use, alcohol, and smoke) were associated with low salivary flow rate in NF1. Moreover, only 4 (8\%) NF1 individuals had plexiform neurofibromas in areas of major salivary glands, which could cause atrophy of the acinar cells by compression or infiltration by the tumor cells, and just one of them had hyposalivation.

Alterations in the salivary glands (acini and ducts) caused by mutations in the NF1 gene may be a possible explanation for the high prevalence of hyposalivation in NF1 individuals. Neurofibromin is a negative regulator of the Ras pathways and there is a complex signaling crosstalks between neurofibromin and other members of the superfamily of small GTPases, including Rho binding domain [13]. Rho family of small GTPases presents a crucial role in lumen morphogenesis of salivary glands in animal models and in acinus formation in human salivary gland

Table 5 Correlation between hyposalivation and its causes and consequences in study group (with NF1)

\begin{tabular}{|c|c|c|c|}
\hline \multirow[t]{2}{*}{ Variables } & \multicolumn{3}{|c|}{ Hyposalivation } \\
\hline & UWSFR & OR (95\% IC) & $P^{*}$ \\
\hline Age & $43 \pm 15.6^{\dagger}$ & - & 0.77 \\
\hline Female/Male & $23 / 6(3.8 / 1)$ & $2.5(0.7-9.0)$ & 0.14 \\
\hline Plexiform neurofibroma close to or involving major salivary glands areas & $1(3.4 \%)$ & $0.2(0.01-2.1)$ & 0.29 \\
\hline Smoker & $1(3.4 \%)$ & $0.2(0.01-2.1)$ & 0.29 \\
\hline Alcohol user & $5(17 \%)$ & $1.1(0.2-5.6)$ & 1.0 \\
\hline Hyposalivation-inducing drugs & $15(51 \%)$ & $1.6(0.5-5.0)$ & 0.41 \\
\hline Intake less than 2 liters of liquid daily & $8(27 \%)$ & $1.7(0.5-5.6)$ & 0.36 \\
\hline Caffeinated or stimulant drink use & $13(44 \%)$ & $1.2(0.3-4.1)$ & 0.68 \\
\hline Mouth breather & $14(48 \%)$ & $1.4(0.4-4.8)$ & 0.51 \\
\hline Oral candidiasis & $7(24 \%)$ & $1.2(0.3-5.0)$ & 1.0 \\
\hline Tongue coating index & $44.4 \pm 27.3^{+}$ & - & 0.05 \\
\hline
\end{tabular}

UWSFR, Unstimulated whole saliva flow rate; OR (95\% IC), Odds ratio and 95\% of confidence interval.

${ }^{*} P$ value is from Qui-square analysis and Fisher's exact tests for categorical variables and Mann-Whitney test for numerical variables; ${ }^{\dagger}$ Results of age and tongue coating index indicate mean \pm standard deviation. 
cell line [13-16]. Kimura et al. [17] showed that neurofibromin is strongly expressed in ductal cells of the parotids. Other salivary glands were not evaluated in that study.

Moreover, the volume and type of saliva is controlled by autonomic nervous system and the blood supply to the glands influences the salivary secretion. Since neurofibromin is expressed in peripheral and central nervous system, as well as in blood vessel smooth muscle and endothelial cells [18-20], alteration in autonomic nervous system and in blood flux to the salivary glands may also be involved in hyposalivation in NF1 individuals.

\section{Conclusions}

Hyposalivation may be a consequence of NF1, as occurs in other genetic diseases. More studies are necessary to understand if there is and what is the relationship between NF1 and hyposalivation.

\section{Availability of supporting data}

The data sets supporting the results of this article are included within the paper and its additional files.

\section{Additional files}

Additional file 1: Details of the clinical data of the study group (NF1 group).

Additional file 2: Details of the clinical data of the control group.

Additional file 3: Details of the results of the oral dryness assessment questionnaire (NF1 group).

\section{Abbreviations}

NF1: Neurofibromatosis 1; TCI: Tongue coating index; UWSFR: Unstimulated whole saliva flow rate; OR: Odds ratio; IC: Confidence interval.

\section{Competing interests}

The authors declared that they have no competing interests.

\section{Authors' contributions}

KSC designed the project, supervised and coordinated the whole process and wrote the manuscript. RRLAP and LVA attended the NF1 participants and collected the data from this group. RRLAP and EBL performed the tongue coating index analysis. EBL, PNA and LMAS obtained the data from the control group. RERM, PNA and EBL participated in writing the manuscript. RERM were involved in statistical analysis and data interpretation. EPD was responsible for cytopathology analysis and critically reviewed the manuscript. All authors read and approved the final manuscript.

\section{Acknowledgment}

The authors thank the Postgraduate Program in Pathology of Universidade Federal Fluminense for its most valuable Oral Diagnosis Ambulatory, which made possible the attendance of NF1 participants. The present research received no specific grant from any funding agency in the public, commercial, or not-for-profit sectors.

\section{Author details}

'Postgraduate Program in Pathology, School of Medicine, Universidade Federal Fluminense, Niterói, RJ, Brazil. ${ }^{2}$ Neurofibromatosis National Center (Centro Nacional de Neurofibromatose), Rio de Janeiro, RJ, Brazil. ${ }^{3}$ School of Dentistry, Universidade Federal Fluminense, Niterói, RJ, Brazil. ${ }^{4}$ Department of Pathology, School of Medicine, Universidade Federal Fluminense, Niterói, RJ, Brazil.
Received: 4 January 2015 Accepted: 10 February 2015

Published online: 28 February 2015

\section{References}

1. Cunha KSG, Geller M. Advances in Neurofibromatosis Research. New York: Nova Science Publishers Inc; 2011.

2. Shapiro SD, Abramovitch K, Van Dis ML, Skoczylas $\amalg$, Langlais RP, Jorgenson RJ, et al. Neurofibromatosis: oral and radiographic manifestations. Oral Surg Oral Med Oral Pathol. 1984;58:493-8.

3. Cunha KS, Barboza EP, Dias EP, Oliveira FM. Neurofibromatosis type I with periodontal manifestation. A case report and literature review. Br Dent J. 2004;196:457-60.

4. D'Ambrosio JA, Langlais RP, Young RS. Jaw and skull changes in neurofibromatosis. Oral Surg Oral Med Oral Pathol. 1988;66:391-6.

5. Bardellini E, Amadori F, Flocchini P, Conti G, Piana G, Majorana A. Oral findings in 50 children with neurofibromatosis type 1. A case control study. Eur J Paediatr Dent Off J Eur Acad Paediatr Dent. 2011;12:256-60.

6. Javed F, Ramalingam S, Ahmed HB, Gupta B, Sundar C, Qadri T, et al. Oral manifestations in patients with neurofibromatosis type-1: a comprehensive literature review. Crit Rev Oncol Hematol. 2014;91:123-9.

7. Stumpf DA, Alksne JF, Annegers JF, Brown SS, Conneally PM, Housman D, et al. Conference statement. National Institutes of Health Consensus Development Conference. Arch Neurol. 1988;45:575-8.

8. Mantilla Gómez S, Danser MM, Sipos PM, Rowshani B, van der Velden U, van der Weijden GA. Tongue coating and salivary bacterial counts in healthy/ gingivitis subjects and periodontitis patients. J Clin Periodontol. 2001;28:970-8

9. Shimizu T, Ueda T, Sakurai K. New method for evaluation of tongue-coating status. J Oral Rehabil. 2007;34:442-7.

10. Picciani BLS, Silva-Junior GO, Michalski-Santos B, Avelleira JCR, Azulay DR, Pires FR, et al. Prevalence of oral manifestations in 203 patients with psoriasis. J Eur Acad Dermatol Venereol JEADV. 2011;25:1481-3.

11. Löfgren CD, Wickström C, Sonesson M, Lagunas PT, Christersson C. A systematic review of methods to diagnose oral dryness and salivary gland function. BMC Oral Health. 2012;12:29.

12. Van der Putten G-J, Brand HS, Schols JMGA, de Baat C. The diagnostic suitability of a xerostomia questionnaire and the association between xerostomia, hyposalivation and medication use in a group of nursing home residents. Clin Oral Investig. 2011;15:185-92.

13. Crema VO, Hamassaki DE, Santos MF. Small Rho GTPases are important for acinus formation in a human salivary gland cell line. Cell Tissue Res. 2006;325:493-500.

14. Xu N, Keung B, Myat MM. Rho GTPase controls invagination and cohesive migration of the Drosophila salivary gland through Crumbs and Rho-kinase. Dev Biol. 2008;321:88-100.

15. Vallée B, Doudeau M, Godin F, Gombault A, Tchalikian A, de Tauzia M-L, et al. Nf1 RasGAP inhibition of LIMK2 mediates a new cross-talk between Ras and Rho pathways. PLoS One. 2012;7:e47283.

16. Ozawa T, Araki N, Yunoue S, Tokuo H, Feng L, Patrakitkomjorn S, et al. The neurofibromatosis type 1 gene product neurofibromin enhances cell motility by regulating actin filament dynamics via the Rho-ROCK-LIMK2-cofilin pathway. J Biol Chem. 2005;280:39524-33.

17. Kimura N, Watanabe T, Fukase M, Wakita A, Noshiro T, Kimura I. Neurofibromin and NF1 gene analysis in composite pheochromocytoma and tumors associated with von Recklinghausen's disease. Mod Pathol Off J U S Can Acad Pathol Inc. 2002;15:183-8.

18. Foster PN, Stewart M, Lowe JS, Atkinson M. Achalasia like disorder of the oesophagus in von Recklinghausen's neurofibromatosis. Gut. 1987;28:1522-6.

19. Okazaki K, Kakita A, Tanaka H, Kimura K, Minagawa M, Morita T, et al. Widespread ischemic brain lesions caused by vasculopathy associated with neurofibromatosis type 1. Neuropathol Off J Jpn Soc Neuropathol. 2010;30:627-33.

20. Danglot G, Régnier V, Fauvet D, Vassal G, Kujas M, Bernheim A. Neurofibromatosis 1 (NF1) mRNAs expressed in the central nervous system are differentially spliced in the $5^{\prime}$ part of the gene. Hum Mol Genet. 1995:4:915-20 